\title{
JUURNAL_RU
}

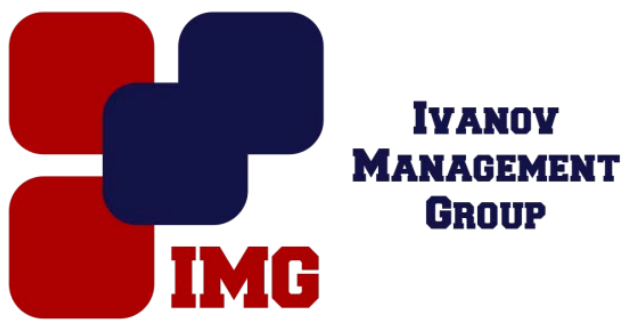

${ }^{1}$ Отрах В.В., ${ }^{2}$ Суконщиков А.А., ${ }^{2}$ Кочкин Д.В., ${ }^{2}$ Бахтенко Е.А. ${ }^{1}$ Московский технологический институт Москва, Россия

${ }^{2}$ Вологодский государственный университет Вологда, Россия

doi: 10.18411/lj-31-01-2017-1-09

idsp 000001:lj-31-01-2017-1-09

\section{Система нечеткого вывода в составе мультиагентной интеллектуальной системы поддержки принятия решений по оперативному рисковому ранжированию контрагентов}

Структура интеллектуальной СППР представлена на рисунке 1 . В левой части схемы представлены источники данных о компании. Данные из всех источников объединяются для формирования профиля компании, который будет использован в системе нечеткого вывода для принятия решения о реструктуризации долга, продолжении сотрудничества, необходимости запроса дополнительных данных от контрагента и т.п. На основе профиля компании производится классификация. Для каждого класса компаний определяются дополнительные правила системы нечеткого вывода, а также веса для общих правил. Такой подход позволяет осуществлять принятие решений с учетом специфики отдельных компаний.

Для формирования базы правил необходимо определить множество входных лингвистических переменных и множество выходных лингвистических переменных .

Отдельная лингвистическая переменная задается следующим образом:

$$
\beta_{i}=<\beta, T, X, G, M>\text {, }
$$

где $\beta$ - наименование лингвистической переменной;

$\mathrm{T}$ - базовое терм-множество лингвистической переменной, каждый элемент которого представляет наименование отдельной нечеткой переменной а. ,. 


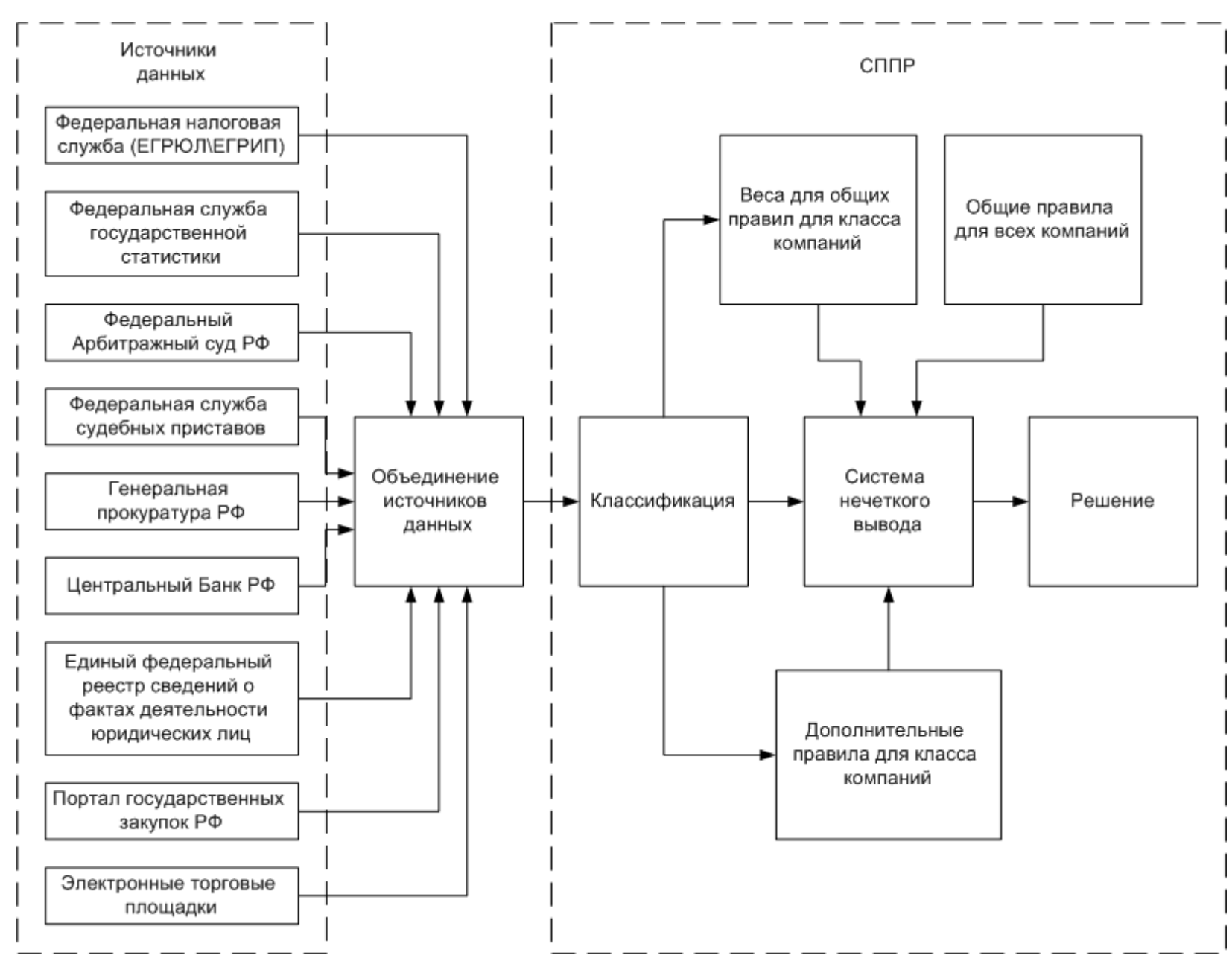

Рис. 1 - Схема СППР

$\mathrm{X}$ - область определения (универсум) нечетких переменных, входящих в ;

G - синтаксическая процедура, описывающая процесс образования из множества Т новых, осмысленных в заданном контексте значений для ; М - семантическая процедура, которая позволяет поставить в соответствие каждому значению, образованному с помощью G, некоторое осмысленное содержание посредствам задания нечеткого множества, определенного на X.

Для задания функции принадлежности термов лингвистических переменных воспользуемся трапецеидальным нечетким интервалом (ТНИ).

$$
A=<a, b, \alpha, \beta>,
$$

где $\mathrm{a}$ и $\mathrm{b}$ - нижнее и верхнее модальные значения ТНИ; и - левый и правый коэффициенты нечеткости ТНИ.

Функция принадлежности в виде ТНИ может быть задана следующим образом: 


$$
f(x ; a, b, c, d)=\left\{\begin{array}{cc}
0, & x \leq a \\
\frac{x-a}{b-a}, & a \leq x \leq b \\
1, & b \leq x \leq c \\
\frac{d-x}{d-c} & c \leq x \leq d \\
0, & x \geq d
\end{array}\right\}
$$

База знаний интеллектуальной СППР может быть определена следующим образом:

$$
R=\left\{R_{1}, R_{2}, \ldots, R_{m}\right\} \mid m \in N,
$$

где - отдельное правило. Каждое правило базы знаний записывается следующим образом:

$$
\left(R_{i}\right): A \Rightarrow B, S, F,
$$

где - ядро правила; А и В - нечеткие высказывания, антецедент и консеквент правила; - знак логического следования; S - метод определения количественного значения степени истинности заключения; F - коэффициент определенности правила. Коэффициент определенности правила может отсутствовать. В таком случае его значение принимается равным единице.

Рассмотрим следующие входные лингвистические переменный с базовыми терм множествами для системы нечеткого вывода:

1. Чистая прибыль (низкая, средняя, высокая);

2. Долг (низкий, средний, высокий);

3. Рост дохода (низкий, средний, высокий);

4. Спад числа сотрудников (низкий, средний, высокий).

Выходная лингвистическая переменная:

1. Риск (низкий, средний, высокий).

Терм множество для входной лингвистической переменной «Спад числа сотрудников» будет выглядеть следующим образом $\mathrm{T}=\{$ Alow, Amed, Ahigh $\}$; Alow $=<0,0,8,12>$, Amed $=<8,12,20,24>$, Ahigh $=<20,24,36,36>$; Функции принадлежности термов входной лингвистической переменной «Спад числа сотрудников» в виде трапецеидальных нечетких интервалов представлены на графике (рисунок 2).

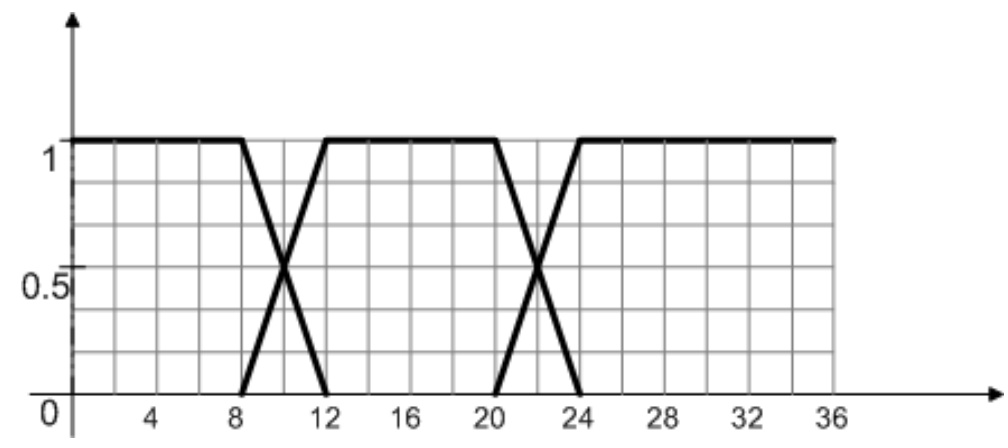

Рис. 2 - Функции принадлежности термов входной лингвистической переменной «Спад числа сотрудников» 
Терм множество для выходной лингвистической переменной «Риск» будет выглядеть следующим образом: $\mathrm{T}=\{$ Alow, Amed, Ahigh $\}$; Alow $=<0,0,20,30>$, Amed $=<20,30,50,60>$, Ahigh $=<50,60,100,100>$; Функции принадлежности термов выходной лингвистической переменной «Риск» в виде трапецеидальных нечетких интервалов представлены на графике (рисунок 3 ).

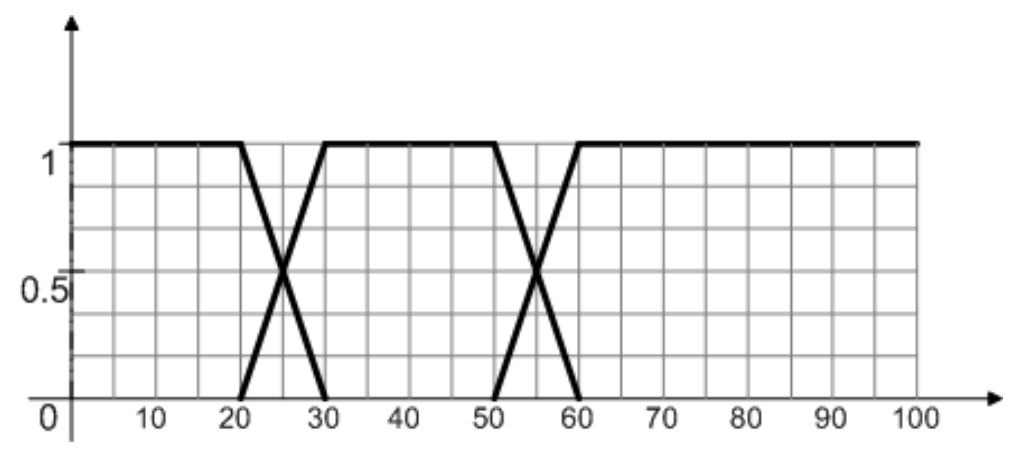

Рис. 3 - Функиии принадлежности термов выходной лингвистической переменной «Риск»

В качестве возможных правил системы нечеткого вывода рассмотрим следующие:

- П1: ЕСЛИ Долг Высокий И ЧистаяПрибыль Низкая И РостДохода Низкий ТО Риск Высокий $\mathrm{F}(\Pi 1)=1$

- П2: ЕСЛИ СпадЧислаСотрудников Высокий ТО Риск Высокий $\mathrm{F}(\Pi 2)=0.5$

- П3: ЕСЛИ СпадЧислаСотрудников Средний ТО Риск Средний $\mathrm{F}(\Pi 3)=1$

Рассмотрим работу системы нечеткого вывода для правил П2 и П3 с коэффициентами определенности $\mathrm{F}(\Pi 2)=0.5$ и $\mathrm{F}(\Pi 3)=1$. Четкое значение входной переменной СпадЧислаСотрудников примем равным 21. Таким образом истинность антецедента правила П2 будет равна 0.25 , а степень истинности антецедента правила П3 будет равна 0.75 .

После выполнения этапов активизации и аккумулирования будет получена функция принадлежности выходной лингвистической переменной «Риск» (Рисунок 4). При выполнении этапа активизации необходимо учитывать веса привил.

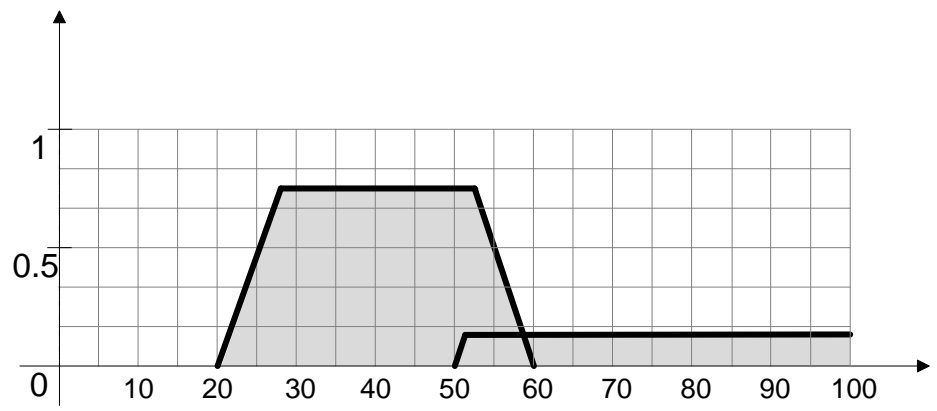

Рис. 4 - Функиия принадлежности выходной лингвистической переменной Риск 
Для получения четкого значения на основе функции принадлежности выходной лингвистической переменной можно воспользоваться одним из существующих методов дефаззификации, например: метод левого модельного значения, метод правого модельного значения, метод центра тяжести.

Для рассмотренных методов дефаззификации четкое значение выходной переменной «Риск» будет:

1. Метод левого модельного значения у $=27,5$;

2. Метод правого модельного значения $\mathrm{y}=100$;

3. Метод центра тяжести $\mathrm{y}=46,8$.

Говоря о нечеткой логике в системах аналитики и управления, можно дать следующее определение системы нечеткого вывода. Система нечеткого вывода это процесс получения нечетких заключений о требуемом управлении объектом на основе нечетких условий или предпосылок, представляющих собой информацию о текущем состоянии объекта. Этот процесс соединяет в себе все основные концепции теории нечетких множеств: функции принадлежности, лингвистические переменные, методы нечеткой импликации и т.п. База правил систем нечеткого вывода предназначена для формального представления эмпирических знаний экспертов в той или иной предметной области в форме нечетких продукционных правил. Таким образом, база нечетких продукционных правил системы нечеткого вывода - это система нечетких продукционных правил, отражающая знания экспертов о методах управления объектом в различных ситуациях, характере его функционирования в различных условиях и т.п., т.е. содержащая формализованные человеческие знания [1].

В заключение отметим, что задание жестких правил невозможно, так как нечеткость присутствует во входных данных по контрагентам, что приводит нас к использованию системы нечёткого вывода, которая позволяет осуществлять адаптивную оценку риска для класса компаний. Также более точный анализ компании-контрагента достигается за счет применения системы нечеткого вывода, содержащей знания экспертов, выраженные в правилах и весовых коэффициентах.

\section{Литература}

1. Суконщиков А.А., Дохтаева И.А. Применение интеллектуальных систем и средств нечеткой логики в автоматическом управлении // Научные исследования: от теории к практике: материалы IV Междунар. науч.практ. конф. — Чебоксары: ЦНС «Интерактив плюс», 2015. - С. 188-189. 